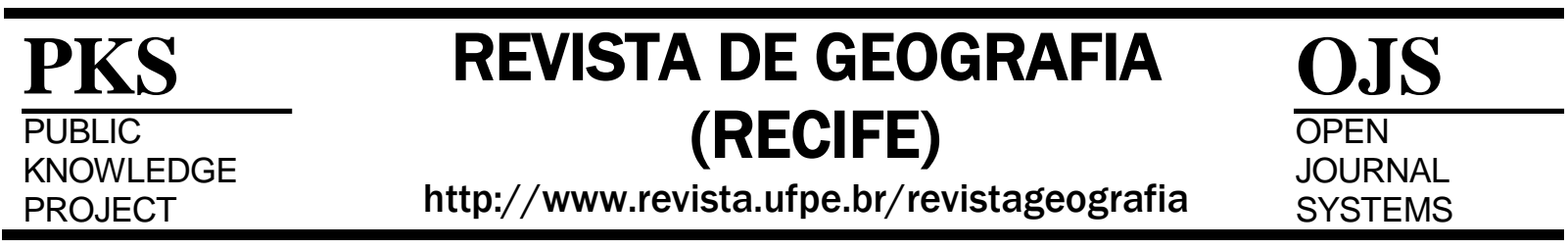

\section{TRANSPATAGÔNIA: PUMAS NÃO COMEM CICLISTAS}

\author{
Alexandre Honig Gonçalves ${ }^{1}$ \\ ${ }^{I}$ Doutorando em Geografia, Universidade Federal da Grande Dourados (UFGD). Email: \\ alexandrehgoncalves@gmail.com
}

Resenha recebida em 01/10/2015 e aceita em 17/03/2016

\begin{abstract}
RESUMO
Esta resenha versa acerca do livro: "Transpatagônia: pumas não comeme ciclistas", escrito por Guilherme Cavallari, em que este narra suas aventuras e desventuras através de Patagônia chilena e da Terra do Fogo argentina. A obra congrega, para além de elementos humanísticos, considerações filosóficas e extensa pesquisa geográfica, histórica e literária acerca da região arduamente percorrida, uma obra diferenciada que descreve o lugar observado e vivdo de maneira importante, estabalecendo a obra como um todo a altura de grandes autores do gênero.
\end{abstract}

Palavras-chave: Transpatagônia; Narrativa de viagem; Aventura; Guilherme Cavallari.

\section{TRANSPATAGONIA: COUGARS DO NOT EAT CYCLISTS}

\begin{abstract}
This review is about the book: "Transpatagonia: Cougars Do not Eat Cyclists", written by Guilherme Cavallari, in which he recounts his adventures and misadventures through Chilean Patagonia and Tierra del Fuego Argentina. In addition, the work brings together a humanistic elements, philosophical considerations and extensive geographical, historical and literary research about the region, this is a differentiated work that describes the place observed and lived in an important way, standing the book as a whole the height of great authors of the genre.
\end{abstract}

Keywords: Transpatagonia; Travel narrative; Adventure; Guilherme Cavallari. 


\section{RESENHA}

$\mathrm{O}$ que vem a ser uma viagem? $\mathrm{O}$ simples ato de se percorrer um determinado caminho, a fim de sair de um lugar geográfico específico e chegar a outro? Os retóricos questionamentos supracitados podem até parecer improcedentes diante das especificidades contemporâneas, em que se expandem as possibilidades pragmáticas de deslocamento e, se democratizam os roteiros turísticos e o acesso aos meios de transporte para efetivá-los (SERRANO, 2014).

Entretanto, o turismo de massas e a forçosa - e, aparente - pasteurização e homogeneização global tornam essa legítima experiência filosófica quase que impossível, uma vez que as perspectivas e as vivências dos turistas inseridos neste contexto são formatadas e fomentadas pelos interesses capitalistas de grandes corporações e são, especialmente, designados e reforçados a partir de campanhas de publicidade extremamente tendenciosas, que buscam ajustar o comportamento social destes viajantes a fim de explorálos ao máximo enquanto agentes consumidores de mais um produto, que neste caso pode ser uma paisagem ou uma experiência "exótica" e efêmera (SWARBROOKE e HORNER, 2002). Por conseguinte, Lévi-Strauss (2004), indicou que o ato de viajar investido e caracterizado enquanto experiência profunda e transformadora se extinguiu.

Todavia, ao tomarmos em mãos o livro: Transpatagônica: pumas não comem ciclistas, publicado em 2015, por Guilherme Cavallari, por meio da editora Kalapalo, podemos questionar seriamente os argumentos preteritamente estabelecidos.

Visto como este não é apenas um livro que narra - brilhantemente - as aventuras e desventuras de um ciclista solitário através de Patagônia chilena e da Terra do Fogo argentina, a obra congrega, para além de elementos humanísticos, considerações filosóficas e extensa pesquisa geográfica, histórica e literária acerca da região arduamente percorrida (CAVALLARI, 2015).

O autor não possui formação acadêmica específica em Geografia, entretanto traz em sua biografia a larga experiência de explorar caminhos - nacionais e internacionais - já conhecidos e, também, selvagens para escrita, produção e editoração de 17 guias de trekking, ciclo turismo e turismo de aventura. Nessas atividades explora o campo como um intrépido geógrafo, pesquisa informações essenciais e preciosas acerca da geomorfologia, da geomorfologia fluvial, dos espaços urbanos, da formação social, econômica e até antropológica do local a ser aprecaido, vivido e descrito. Para tanto, se utiliza de cartas 
topográficas, mapas, entrevistas, fotografias, fontes secundárias e equipamentos de georreferenciamento, estabelecendo a partir de métodos, técnicas e procedimentos de pesquisa basicamente geográficas: novas perspectivas críticas e, materiais didáticos e práticos que vêm a servir de apoio e orientação aos viajantes que se utilizam de seus textos posteriormente.

O autor viveu e trabalhou nos Estados Unidos, na Inglaterra, em Israel, na Itália e na Alemanha, além de ter viajado por quatro continentes. A partir de seu perfil e histórico individual, de suas experiências literárias e - principalmente - das vividas, o autor de Transpatagônia (...), estabelece ao longo das laudas de seu livro, diálogos dinâmicos a partir de uma perspectiva singular, racional e equilibrada, em que a geografia do local segue como sendo o objeto de ênfase e plano de fundo a sensível captação das nuances de vários personagens e contextos que habitam o ambiente transfronteiriço em questão.

Especificamente, o livro registra, traz em voga e descreve em 50 capítulos, os principais pontos da longa viagem de bicicleta por toda a extensão da Patagônia e da Terra do Fogo, no extremo sul da América do Sul - foram $6.000 \mathrm{~km}$ em 180 dias, cruzando a fronteira entre a Argentina e o Chile por 16 vezes -, exposto a toda sorte de intempéries climáticas, singrando rios e lagos gélidos, percorrendo estradas desérticas, abrindo novas trilhas em bosques selvagens, escalando montanhas e contemplando paisagens únicas no planeta Terra.

Além disso, esta é uma narrativa diferenciada na literatura mundial de viagens sobre a região, uma vez que o observador não passou estanque, hostil e preconceituoso sobre a realidade que o cercava - ao contrário -, interagiu visceralmente com a fauna, a flora e, sobretudo com a sociedade local - com suas culturas, tradições e lutas tão específicas e distintas de sua própria realidade.

Redigido a partir de uma escrita prodigiosa, cheia de descrições maravilhosas sobre o lugar e de histórias intrigantes, descreve seus encontros com outras pessoas e situações históricas e contemporâneas -, conferindo ao texto uma dimensão filosófica, poética, mágica, intensa e, ainda: inspiradora.

Valem destacar os argumentos acima nesta resenha, uma vez que um dos relatos de viagem mais famosos e reconhecidos mundo a fora acerca deste lugar: Na Patagônia, escrito por Bruce Chatwin, originalmente em 1977, relata o lugar a partir de um ponto de vista agressivo e de autodistinção, descrevendo uma sociedade segregada, habitada somente por figuras errantes e exiladas, de gaúchos solitários a salteadores foragidos, mineiros abandonados e índios impetuosos. Especificamente, nesta crônica a natureza local é secundarizada e minimizada frente às perspectivas e expectativas de imigrantes - 
conquistadores -, que buscavam a todo custo adaptar o local às suas demandas específicas, mesmo que a força, denegrindo e exaurindo as potencialidades socioambientais naturais do ambiente (CHATWIN, 2011). Em contrapartida, com o livro de Cavallari - em diversas passagens -, o leitor é levado ao ato da reflexão acerca da importância de conhecer, reconhecer e perceber os sujeitos locais como sendo protagonistas do lugar ao qual pertencem e se fazem pertencer, em que estabelecem vínculos sociais e com a própria natureza, mesmo que de uma forma dessemelhante daquela em que estamos inseridos - nem melhor, nem pior: diferente.

A proeza desta obra situa-se justamente na ênfase que é dada à noção de lugar e, igualmente, na ideia de que a plenitude da vida cotidiana pode ser alcançada sem que se esteja soterrado em ambientes urbanos - tendo a vida regida diretamente por julgamentos, imposições sociais, comerciais e de interesses difusos, que não os do próprio sujeito (PIRES, 2007). Por sua vez, a leitura fomenta a construção de uma relação interativa com o lugar por meio da aplicação de práticas e saberes autônomos, que se constituem a partir da diversidade e das apropriações espaciais do modo mais adequado possível.

Desta feita, Transpatagônia (...) conduz ao leitor a modificar seu olhar sobre os sujeitos que se inserem nos espaços da Patagônia e da Terra do Fogo, mas também daqueles que passam por ali apenas como viajantes transitórios. As múltiplas identidades dos sujeitos e dos lugares se agregam, gerando sentimentos contraditórios - de admiração e amor à repulsa e ódio - sobre o lugar. Assim sendo, o exame e estudo deste livro trazem consigo a evidente preocupação de se deslocar o olhar do leitor aos sujeitos e ao ambiente descritos, visto como o lugar evoca relações subjetivas que rompem a visão fragmentada e reducionista acerca do espaço e das interações que se desenvolvem sobre este. Notadamente as tessituras territoriais entrelaçadas pelas diferentes práticas socioculturais e apropriações concretas e simbólicas do espaço (PIRES, 2007).

Nesse sentido, o livro Transpatagônia: pumas não comem ciclistas, é um livro essencial àqueles que buscam uma leitura dinâmica, em que possam observar, por meio de uma narrativa impecável, as conexões e aplicações entre a história, a geografia, as relações internacionais, a economia e a política de um ambiente único - tão próximo e ao mesmo tempo, tão distante do Brasil. Este é um livro de literatura de viagens excepcional, que deve ser lido com avidez e, só posteriormente, colocado a descasar na estante, bem ao lado de importantes autores - clássicos e contemporâneos -, como: Orlando Villas Bôas e Cláudio 
Villas Bôas ${ }^{1}$ (brasileiros), Amyr Klynk ${ }^{2}$ (brasileiro), Almeida Garret ${ }^{3}$ (português), Carlos Carneiro $^{4}$ (português), Cheryl Strayed ${ }^{5}$ (norte-americana), Paul Theroux ${ }^{6}$ (norte-americano), Antoine de Saint-Exupéry ${ }^{7}$ (francês), Robyn Davidson ${ }^{8}$ (australiana), dentre tantos outros expoentes desta classe literária.

Por fim, para responder os questionamentos aviltados logo na primeira linha deste breve texto, tomei emprestadas as palavras de Cavallari (2015):

\begin{abstract}
"Como alguém pode estar preparado para o desconhecido, o imprevisto, o incerto? O que é uma viagem de verdade senão exatamente isso? (...), não vejo por que sair de casa se já sei o que vou encontrar lá fora (p. 20-21)”.

"Vou viajar seis meses de bicicleta e acampar por toda a Patagônia e a Terra do Fogo. Vou explorar também alguns trechos a pé, caminhar onde não há trilhas, subir montanhas, cortar parques, cruzar rios sem pontes, visitar lugares realmente remotos e isolados. Tudo sozinho, independente, autossuficiente. Quero ficar frente a frente com um puma solto na natureza! (p. 17)".
\end{abstract}

\title{
AGRADECIMENTOS
}

A FUNDECT MS pela concessão de bolsa de estudo ao autor da resenha.

\section{REFERENCIAS}

CAVALLARI, GUILHERME. Transpatagônica: pumas não comem ciclistas. São Paulo: Editora Kalapalo, 2015, 335 p.

CHATWIN, B. Na Patagônia. Lisboa: Editora Quetzal, 2011, 398 p.

LÉVI-STRAUSS, C. Tristes Trópicos. Lisboa: Edições 70, 2004.

PIRES, C. L. Z. Saberes e práticas na construção de sujeitos e espaços sociais: educação, geografia, interdisciplinariedade (Resenha). Rev. Terra Livre. v. 23. n. 28. 2007.

SERRANO, S. Mulheres viajantes. Lisboa: Tinta da China, 2014, 342 p.

SWARBROOKE, J.; HORNER, S. O comportamento do consumidor no turismo. São Paulo: Editora Aleph, 2002, 405 p.

\footnotetext{
${ }^{1}$ Autores de: A marcha para oeste: a epopeia da expedição Roncador-Xingu; Histórias do Xingu;

${ }^{2}$ Autor dos títulos: Cem dias entre céu e mar; Paratii: entre dois polos; As janelas do Paratii; Mar sem fim: $360^{\circ}$ ao redor da Antártida; Linha d`água: entre estaleiros e homens do mar;

${ }^{3}$ Autor de: Viagens na minha terra, dentre outros;

${ }^{4}$ Autor de: Nunca é tarde: o reencontro entre pai e filho num longa viagem à volta de África; Até onde vais com 1000 Euros?;

${ }^{5}$ Autora de: Wild: from Lost to Found on Pacific Crest Trail;

${ }^{6}$ Autor de: The great railway bazar; The old Patagonian express, dentre outros;

${ }^{7}$ Autor de: Corrier sud; Vol de nuit; Terre des hommes; Pilote de guerre; Le petit prince;

${ }^{8}$ Autora de: Tracks; Desert Places. 